\title{
A TRANSIÇÃO TECNOLÓGICA NA SAÚDE: DESAFIOS PARA A GESTÃO DO TRABALHO
}

\author{
TECHNOLOGICAL TRANSITION IN HEALTH WORK; \\ CHALLENGES FOR THE MANAGEMENT OF HUMAN RESOURCES
}

Maria Inês Carsalade Martins 1

Resumo Este artigo é parte de um estudo empírico sobre as mudanças no trabalho em saúde, em função da incorporação de novas tecnologias. O estudo caracteriza-se por uma abordagem interdisciplinar e o referencial teórico que orienta a pesquisa tem como base os conceitos de reestruturação produtiva, competência e subjetividade. Tendo como foco a organização dos serviços e as novas demandas para os trabalhadores de nível médio do ponto de vista da sua qualificação, a pesquisa analisa a relação homem/trabalho na perspectiva das mudanças tecnológicas, das competências laborais, da autonomia, da comunicação e da linguagem. Os resultados do estudo indicam algumas tendências do processo de trabalho que apontam a tecnologização da assistência e do trabalho em equipe, e a necessidade do desenvolvimento profissional e de reestruturação do trabalho em saúde. Entre os desafios levantados, destacam-se a valorização do trabalho e do trabalhador, a incorporação do conceito de competência, o reconhecimento das relações subjetivas e o processo de comunicação.

Palavras-chave gestão do trabalho em saúde; mudanças tecnológicas; competência; subjetividade.
Abstract This article is part of an empirical study about changes in health work due to the introduction of new technologies. The study uses an interdisciplinary approach and the theoretical referential orienting the research has as bases the concepts of productive restructuring, competency and subjectivity. Focusing on the organization of the services and on the demands for further qualifications for secondary level workers, the research analyses the relation human being/work from the perspective of technological changes, work competences, autonomy, communication and language. The results indicate some trends in the health work process that point to the technologizing of care, to teamwork, and to the need for professional development and for a restructuring of the work in this area. Among the challenges that need to be faced, we emphasize the valorization of both work and worker, the incorporation of the concept of competency, the recognition of subjective relationships and the communication process.

Key words human resources; health; technology; competency; subjectivity. 


\section{Introdução}

A discussão sobre um novo paradigma do trabalho nas sociedades pós-industriais, que se origina nas décadas de 80 e 90 a partir da reestruturação produtiva, recoloca a centralidade do trabalhador no processo produtivo e amplia a discussão sobre os processos de qualificação.

A partir de uma revisão da literatura, é possível identificar que está em curso uma transformação significativa, caracterizada por uma transição do modelo taylorista/fordista - que vigorou entre os anos 50 e 70, no qual a organização do trabalho se caracterizava pela dominância do trabalho prescrito, com poucas possibilidades de intervenção nos processos produtivos e pouca autonomia dos trabalhadores - para um modelo tecnológico baseado na intelectualização do trabalho, cujas principais referências passam a ser o conhecimento técnico e a qualificação profissional2 (Boyer e Durand, 1993).

Neste novo cenário, é possível identificar, na literatura do âmbito das relações e da natureza do trabalho em saúde, novas temáticas: autonomia, flexibilização, diversificação dos serviços, qualidade dos serviços em contraponto à qualidade técnica, novos processos de qualificação dos trabalhadores, humanização e subjetividade. Tais temas merecem uma reflexão e um esforço de aprofundamento, no sentido de relacioná-los ao atual contexto de reorganização do mundo do trabalho3.

Do ponto de vista do gerenciamento, o debate se coloca na perspectiva do aumento da produtividade e da complexidade dos objetos de trabalho, que passam a requerer, ao mesmo tempo, um aprofundamento vertical do conhecimento especializado e sua integração.

Ao analisar as mudanças que vêm ocorrendo no mundo do trabalho a partir da reestruturação produtiva e do desenvolvimento tecnológico, na perspectiva do setor terciário, mais especificamente em relação ao trabalho em saúde, é importante não só reconhecer a centralidade do trabalho humano no que se refere às suas competências laborais, mas também resgatar o caráter subjetivo da ação humana no processo de trabalho.

Trazer esta discussão para o campo da saúde torna-se ainda um desafio, porque, em primeiro lugar, trata-se de uma área multi e interdisciplinar, que compreende um largo espectro de atividades de produção e de serviços, que abrangem desde a indústria de equipamentos e medicamentos à prestação de serviços médicos, em nível hospitalar, ambulatorial ou de unidades de saúde, passando pela produção de conhecimento e informação; em segundo lugar, o foco principal destas atividades são pessoas, e, portanto, o processo de trabalho é pautado no contato humano e na relação entre elas.

Quanto ao primeiro item, a tecnologia constitui uma categoria-chave para explicar as mudanças observadas a partir do processo de inovação na área de saúde, sobretudo na área da medicina intensivista e nos serviços de apoio 
diagnóstico, em que sua participação tem ocorrido de forma mais direta. Por outro lado, o debate atual sobre as novas formas de organização do trabalho resgata a discussão da qualificação profissional como outro elemento-chave na compreensão dessas novas formas, articulando, do ponto de vista teórico, os campos do trabalho e da educação. Nesta linha, o modelo de competências tem ganhado centralidade, sendo um instrumento valioso de interpretação da realidade do trabalho nos dias atuais, por incorporar a experiência e os conhecimentos advindos da prática dos serviços. Para Zarifian (1990), competência seria a capacidade de enfrentar situações e acontecimentos próprios de um campo profissional, com iniciativa e responsabilidade, guiadas por uma inteligência prática do que está ocorrendo e com capacidade para se coordenar com outros atores a fim de mobilizar suas capacidades.

No campo da saúde, o conflito que se instala com essa transição abre espaço para uma reflexão sobre as implicações dos diferentes modelos e as possíveis alternativas no sentido da humanização do trabalho e da melhoria da assistência. Sobre o assunto, destacam-se as contribuições de Dal Poz (1998), Peduzzi (1998) e Pires (1988).

Com base nesta discussão, realizamos uma pesquisa que, a partir da identificação de um espaço institucional estruturado no contexto das mudanças tecnológicas, procurou observar as tendências do trabalho em saúde, analisando sua organização e gestão, bem como as formas de adaptação dos trabalhadores às mudanças no processo de trabalho.

Este artigo sintetiza os resultados dessa pesquisa, realizada em um centro cardiológico inaugurado em 1998, em um hospital privado da cidade do Rio de Janeiro, que, na época, tinha como meta tornar-se um serviço de referência. Montado segundo padrões modernos - com equipamentos de ponta, pessoal qualificado e grande investimento em formação de pessoal e pesquisa clínica, suas atividades estavam voltadas para as demandas do mercado 4 .

O ambiente hospitalar constituiu um locus privilegiado para este tipo de estudo, já que representa, além do local de maior incorporação tecnológica, o espaço legitimador da prática médica assistencial, onde a hierarquia das profissões de saúde aparece de maneira mais clara. Para Machado e Correa, o objeto do trabalho hospitalar é complexo, mas é também humano, interage com o trabalhador e o processo de produção depende da cooperação do objeto de trabalho. Ainda segundo os autores, "o caminho que o hospital percorre em sua história como instituição aponta sua transformação de depositário de doentes e excluídos em lócus de extrema concentração de tecnologia e saber" (Machado e Correa, 2000, p. 96). 


\section{0 desenho da pesquisa}

A pesquisa traz na definição de seu objeto um importante ponto de inflexão para os estudos na área de recursos humanos em saúde: o trabalho do técnico na perspectiva da inter-relação entre a prática e a norma, definida por nós como 'trabalho real'.

Ao definir o trabalho real como objeto de investigação, estamos priorizando um enfoque que incorpora a dimensão subjetiva do trabalho. Assim, o trabalho real5 é entendido, nesta proposta de investigação, como resultante da confrontação do sujeito com a realidade do trabalho, e o que de fato está se passando no mundo real do trabalho é a pergunta que traduz a direção de nossa pesquisa.

Na discussão atual sobre a reorganização do trabalho, tem sido privilegiado e destacado a importância do trabalhador de nível médio e o papel estratégico que ele ocupa. Este debate vem tendo como eixo as novas exigências do mercado em relação ao perfil desses trabalhadores, os processos de qualificação e a regulação e normalização de seu trabalho, que exigências se colocam para o tecnologista em relação ao trabalho em saúde?"

Em nosso entender, é necessário introduzir, nesta discussão, a análise dos processos subjetivos e intersubjetivos e as relações entre os indivíduos e as organizações que caracterizam a prática real do trabalho, sobretudo em se tratando do trabalho em saúde.

Ao aprofundar a questão da subjetividade na perspectiva da psicodinâmica do trabalho, Déjour e Abdoucheli (1990) formulam a idéia de uma inteligência astuciosa, que se desenvolve com base nas percepções e na sensibilidade do agente e procura adaptar os moldes operatórios prescritos às necessidades do cotidiano do trabalho, a fim de alcançar os objetivos de forma mais eficaz. Este comportamento seria ativado pelo encontro do sujeito com uma situação de trabalho, cuja tarefa faça algum sentido ou alguma ponte com sua história anterior6.

O caráter intersubjetivo das relações que se estabelecem entre os diferentes sujeitos (prestadores e receptores dos serviços de saúde) faz com que estruturas, normas, políticas institucionais, descrição de tarefas e procedimentos atuem como referências primárias que, a partir de uma interação simbólica, irão se transformar em trabalho real.

Considerando que entre o homem e a atividade prescrita abre-se um espaço de liberdade que permite, pelo uso da criatividade e da negociação, sua intervenção no processo de trabalho por meio da utilização de estratégias defensivas 7 , podem ser geradas novas formas de organização do trabalho, construídas e validadas coletivamente.

Estas novas regras, construídas pelos trabalhadores no espaço de trabalho, quando estabilizadas, apropriadas pelo coletivo dos trabalhadores, 
ajudam na gestão das dificuldades encontradas no desenvolvimento do trabalho.

As regras de ofício ultrapassam a dimensão individual, estabelecendose como formas singulares de organização do trabalho, que passam necessariamente por conteúdos de diversas naturezas: prática (técnica), relacionada ao 'como fazer'; comportamental (social), relacionada ao 'como interagir'; lingüística, relacionada a sua própria socialização e legitimação; e ética, como forma de mediar e arbitrar os conflitos decorrentes das relações de trabalho.

Para o trabalhador, o conteúdo significativo do seu trabalho, o nível de satisfação ou insatisfação que este gera e seus limites frente ao medo e à angústia, inerentes à situação de trabalho, são fontes de conflito que ele tem que enfrentar como sujeito, agente do trabalho.

Assim, a noção de sofrimento, outra categoria de análise abordada por Déjour e Abdoucheli (1990), resulta da maneira como o trabalhador se movimenta no espaço constituído entre o trabalho prescrito e o trabalho real, mais precisamente como ele reage às pressões psíquicas da organização do trabalho.

Ao trazer esta discussão para o campo do trabalho em saúde, percebemos o quanto estas categorias - sofrimento e estratégias defensivas, oriundas da psicopatologia do trabalho - podem contribuir para o entendimento do processo de trabalho em saúde e os conflitos e as contradições que ele encerra.

Optou-se, assim, por desenvolver uma estratégia metodológica capaz de integrar os aspectos subjetivos, intersubjetivos e operacionais do processo de trabalho que possibilitasse relacionar contexto, atributos e tarefas, incorporando a dimensão filosófica - relacionada à ética, aos valores e a uma prática reflexiva e crítica; a dimensão psicológica - que envolve o pensamento prático e as relações decorrentes do encontro da situação de trabalho e da história singular dos trabalhadores; e a dimensão política - que diz respeito às formas de organização do trabalho e ao resgate do trabalhador como sujeito social8.

A observação direta das atividades dos agentes que realizam o trabalho - suas relações com a tarefa, com os companheiros de trabalho, com a hierarquia e suas formas de organização - bem como a realização de entrevistas com alguns profissionais participantes foram as estratégias que julgamos as mais adequadas para relacionar o trabalho prescrito e o trabalho real, de forma a melhor compreender a organização do trabalho em saúde, a partir da reestruturação produtiva.

O plano de trabalho constou, numa primeira etapa, de entrevistas com diretores ${ }^{9}$ e coordenadores das diferentes áreas, de forma a identificar a proposta da Unidade, a dinâmica do trabalho e as relações sociais que se estabeleciam naquele contexto ${ }^{10}$. Com base nas entrevistas, foram definidas estratégias para o trabalho de campo - observação participante e aplicação de questionário a todos os funcionários. 
No trabalho de campo, realizado entre abril e maio de 2001, foram observadas, sobretudo, as estratégias defensivas, a linguagem e as regras de ofício, as relações hierárquicas, as instâncias decisórias, a rotatividade das funções, os processos de comunicação e as formas de adaptação do sujeito à realidade do trabalho.

Do total de 76 funcionários que responderam aos questionários, 60 profissionais $(79 \%)$ estavam diretamente ligados a atividades de assistência (17 médicos 11,7 enfermeiros 12 e 36 técnicos de enfermagem), 10 funcionários à área administrativa e 2 aos serviços de limpeza (higienização), para o atendimento de 15 leitos.

A análise do material empírico, a partir desse desenho, trouxe um conjunto de informações que se constituíram na base para a nossa investigação sobre o impacto das mudanças no mundo do trabalho, especificamente no campo da saúde, na perspectiva do processo de trabalho, do impacto das novas tecnologias, da qualificação, da comunicação e das estratégias de defesa, conforme descrevemos nos itens a seguir.

\section{O processo de trabalho}

O processo de trabalho na área hospitalar e principalmente nas Unidades Intensivistas está pautado, basicamente, em atividades assistenciais que se diferenciam em função da inserção de cada profissional na equipe, em que as atividades são realizadas de forma diferenciada, cabendo a cada grupo profissional uma parte do processo. Aos médicos cabe o cuidado médico, procedimentos clínicos invasivos e não-invasivos, as atividades de pesquisa científica e, sobretudo, a decisão técnica em relação aos procedimentos a adotar; aos enfermeiros, o planejamento das ações de enfermagem, a supervisão técnica e o gerenciamento do setor; aos técnicos, cuidados gerais de enfermagem, administração de medicamentos, auxílio em procedimentos médicos; aos administrativos, o atendimento ao público, admissão de pacientes e controle dos gastos.

Embora no desenvolvimento da rotina assistencial o trabalho coletivo se mostre de forma articulada, o que se pode observar do ponto de vista do cuidado com a saúde é um conjunto de ações fragmentadas, realizadas de maneira conjunta, ocorrendo apenas no nível instrumental da tarefa a ser executada e em busca de um resultado imediato, sem nenhuma relação no plano da comunicação. A ausência do espaço de discussão do processo de trabalho dificulta a interação entre os agentes.

Esta relação só é quebrada nas situações de emergência, comuns neste tipo de atividade, quando toda a equipe atua de forma solidária e articulada, sob a liderança do profissional médico, sendo o produto final reconhecido como fruto de um trabalho coletivol3. 
Uma das características do processo de trabalho observado é a utilização de protocolos de atendimento para as situações e evidências que surgem em relação aos problemas de saúde. Esta é uma tendência da organização do trabalho, que se institucionaliza nos hospitais por meio do processo de acreditação. É um procedimento que, se por um lado garante um padrão de qualidade e instrumentos de avaliação do serviço prestado, por outro interfere na autonomia técnica e dificulta o processo de interação, uma vez que procura retirar qualquer aspecto subjetivo e altera o processo decisório.

A Tabela 1 retrata a percepção dos funcionários em relação aos desgastes mais freqüentes na situação de trabalho que vivenciam. As respostas foram agregadas por categoria de análise, independentemente da categoria profissional do interlocutor, tendo-se admitido mais de uma resposta.

\section{Tabela 1}

Principais desgastes em relação ao processo de trabalho na Unidade Coronariana, na percepção dos trabalhadores

\begin{tabular}{lc}
\hline No exercício do trabalho & Total de respostas \\
\hline Depende de muita força muscular & 7 \\
Despende muita energia & 7 \\
Exige memorização & 8 \\
Manipula objetos perigosos & 21 \\
Necessita reter muitas informações & 8 \\
Tem fadiga física geral & 13 \\
Tem fadiga mental & 24 \\
Tem que estar atento ao sistema de sinalização visual e sonoro & 30 \\
Tem que estar em vigilância permanente & 26 \\
Utiliza conhecimento ou técnica específica & 75 \\
\hline
\end{tabular}

Com base nestas respostas, é possível constatar uma tendência à substituição do trabalho físico intensivo por uma atividade mais intelectualizada, que exige alto nível de atenção e conhecimentos específicos. A fadiga física, característica do modelo taylorista, é substituída pela fadiga mental, característica do modelo tecnológico.

Quanto às exigências oriundas do processo de trabalho, ao serem indagados sobre as principais habilidades requeridas, os trabalhadores priorizaram os fatores indicados na Tabela 214 . As células grifadas referem-se ao total de trabalhadores que colocou aquelas respostas entre as suas três primeiras opções. 


\begin{tabular}{|c|c|c|c|c|c|c|c|c|}
\hline Habilidades/Prioridades & $\begin{array}{c}1 \underline{a} \\
\text { opção }\end{array}$ & $\begin{array}{c}2 \underline{a} \\
\text { opção }\end{array}$ & $\begin{array}{c}\text { 3ạ } \\
\text { opção }\end{array}$ & $\begin{array}{c}4 \underline{a} \\
\text { opção }\end{array}$ & $\begin{array}{c}5 \underline{a} \\
\text { opção }\end{array}$ & $\begin{array}{c}\text { 6ạ } \\
\text { opção }\end{array}$ & $\begin{array}{c}\text { 7ạ } \\
\text { opção }\end{array}$ & $\begin{array}{c}8 \underline{a} \\
\text { opção }\end{array}$ \\
\hline Atenção & 21 & 5 & 2 & - & - & 2 & - & - \\
\hline Experiência & 4 & 7 & 9 & - & 2 & 1 & 3 & 3 \\
\hline Conhecimentos atualizados & 4 & 7 & 3 & 5 & 1 & 6 & 1 & - \\
\hline Conhecimentos dos equipamentos & - & 3 & 4 & 5 & 7 & 2 & 2 & 4 \\
\hline Habilidade para lidar com pessoas & 1 & 2 & 6 & 6 & 4 & 7 & 3 & - \\
\hline Facilidade de trabalho com a equipe & - & 4 & 4 & 6 & 4 & 2 & 6 & 3 \\
\hline Capacidade de comunicação & 1 & 2 & 1 & 4 & 8 & 4 & 6 & 3 \\
\hline Criatividade & - & 1 & 2 & 2 & 1 & 3 & 6 & 12 \\
\hline
\end{tabular}

As opções assinaladas como as três mais importantes foram: capacidade de atenção - 27 pessoas colocaram entre as três primeiras opções; experiência - 20; conhecimentos atualizados - 14. Entre as habilidades citadas nas três últimas opções, estão criatividade (21 respostas); capacidade de comunicação (13); facilidade para lidar com a equipe (11).

Essas respostas evidenciam a hegemonia do saber técnico, baseado na fundamentação científica, sobre o 'saber ser'15, que constitui uma competência essencial para que o processo de trabalho se realize numa base interativa e intersubjetiva e, no caso da saúde, com a garantia de humanização do atendimento.

A habilidade para lidar com pessoas aparece na média das escolhas, e a facilidade para trabalhar em equipe, embora apareça entre as últimas opções, foi muito apontada pelos técnicos de enfermagem.

\section{O impacto das novas tecnologias}

A tendência que se observa na assistência hospitalar é de ampliação da oferta de serviços de maior complexidade, que pode ser percebida pelo aumento do número de postos de trabalho e pela qualificação exigida para os mesmos.

O binômio tecnologia-qualificação coloca-se como um princípio básico para o desenvolvimento do trabalho e está presente na fala de gestores, técnicos e coordenadores. A criação de um programa específico de capacitação na Unidade Coronariana demonstra a preocupação com a qualificação do pessoal.

Ainda quanto ao processo de incorporação tecnológica, a discussão com dirigentes, coordenadores técnicos e profissionais de nível superior trouxe à tona uma questão importante em relação à formação profissional no con- 
texto de reestruturação produtiva e mudanças na relação do Estado com a sociedade: o papel do setor público na formação dos profissionais de saúde e os novos modelos de certificação, entre os quais destacamos os de certificação de qualidade e os modelos de capacitação e educação a distância e de acreditação.

Neste novo cenário que se delineia, o Estado, aos poucos, vai abrindo mão do controle e da regulação de atividades essenciais à sociedade, como saúde e educação, transferindo ao mercado a responsabilidade. Esta é uma questão que não aprofundaremos aqui, mas que merece ser sinalizada e posteriormente discutida.

\section{As competências}

Para Zarifian, o modelo de competência advém de uma mudança profunda nas organizações do trabalho e nas relações sociais nas empresas, mais do que propriamente da mudança dos conteúdos do trabalho com a introdução das inovações tecnológicas. Assim, para ele, há uma distinção entre competência (no singular), que se refere a mudanças nas organizações e nas relações sociais, e competências (no plural), que se refere às modificações nos conteúdos profissionais (Zarifian, 1998a).

Assim como do ponto de vista teórico não há consenso sobre a definição de competência, na prática foi possível perceber que as visões também se misturam, embora o discurso tecnológico predomine.

Se recuperarmos a discussão de Zarifian sobre as transformações do trabalho, a qualidade 'vigilância' estaria relacionada, neste novo contexto, à atividade de supervisão, esta não na perspectiva de 'tomar conta', mas de uma vigilância ativa, exercida no decorrer do trabalho, a partir de informações fornecidas pelos processos informatizados comparados a parâmetros preestabelecidos. No caso da unidade estudada, a vigilância ativa teria como fornecedor de informações os equipamentos de monitoração dos pacientes.

No conjunto das competências menos citadas, como analisado na Tabela 2, destacam-se no conjunto de 37 entrevistados: a capacidade de trabalhar em equipe, colocada por 11 entrevistados entre as três últimas opções; em seguida, a capacidade de comunicação, citada por 13 deles e, finalmente, a criatividade que aparece entre as três últimas opções para 21 entrevistados.

A dicotomia entre a concepção do trabalho e sua organização, na prática, pode ser observada na fala dos coordenadores e trabalhadores quando se referem às qualidades e habilidades desejáveis e à sua priorização na situação de trabalho. Embora tida como um dos fatores fundamentais para as empresas, mesmos nos setores mais racionalizados e tecnologizados, a cria- 
tividade não é percebida como tal por este grupo, já que não é demandada no cotidiano do trabalho.

O trabalho em equipe, embora no contexto geral dos depoimentos não apareça como prioridade, para o grupo dos técnicos foi considerada a principal qualidade - "trabalhar de forma cooperativa, cooperar, saber trabalhar em equipe". Este grupo vive na prática a contradição do modelo de transição, em que o desenvolvimento tecnológico exige uma organização mais flexível, integrada e interativa do trabalho, enquanto o modelo tradicional de organização no campo da saúde se mantém superespecializado, fragmentado e repetitivo.

Observa-se que, apesar do discurso, na prática, a forma de organização do trabalho mantém os padrões tradicionais de fragmentação, reduzindo o espaço para o exercício da autonomia, da criatividade e da negociação. Assim, embora a concepção do modelo aponte a necessidade de um trabalhador polivalente, escolarizado e participativo, a forma pela qual o trabalho de 'equipe' se organiza restringe a participação deste trabalhador.

A implementação da mudança para um modelo de organização do trabalho e de relações sociais baseadas na incorporação e integração de saberes técnicos, operacionais, comportamentais e políticos ocorre de maneira lenta e pontual, apesar de apontada como uma necessidade por trabalhadores e gestores, de forma diferente, em função da sua inserção na equipe.

Este, no entanto, é um processo que demanda mudanças na política de gestão da força de trabalho; investimento nos processos de formação e desenvolvimento de equipe; envolvimento dos trabalhadores nos processos de mudança quanto ao conteúdo e à sua implementação, não sendo, uma conseqüência 'natural' das inovações tecnológicas, como alguns consideram.

A reificação da tecnologia, encarada como a razão e o princípio que orientam as práticas 'modernas' de saúde, faz com que esta seja a primeira resposta quando o objeto de discussão é o processo de trabalho em unidades desta natureza. Uma vez assumida esta premissa, os trabalhadores se permitem apontar outros requisitos, mais subjetivos, igualmente necessários à prática da assistência, mas não legitimados do ponto de vista do paradigma tecnológico. Assim, qualidades como companheirismo, humanidade, capacidade de comunicação, respeito, paciência e vocação são citadas como requisitos ao trabalho, mas num segundo plano.

Mais uma vez, o discurso hegemônico é o da supremacia do saber técnico e do saber fazer sobre os outros saberes, principalmente do saber ser, e a humanização do atendimento aparece de forma residual, como uma competência básica para o trabalho em saúde. É como se fosse necessário escolher entre a técnica e a humanização do atendimento.

A oposição entre subjetividade e objetividade, humanização e competência técnica presente no discurso de profissionais, gestores e clientes re- 
flete a tendência 'tecnologizante' da sociedade que acompanha o processo de modernização, que, segundo Habermas (1968), legitima a dominação a partir de uma forma específica de conceber o mundo.

A ambigüidade das equipes na relação com a instituição - provocada pela terceirização parcial, em que o serviço médico pertence a um grupo recrutado, contratado, treinado e remunerado com uma lógica e uma coordenação própria, e o serviço de enfermagem, que pertence ao hospital, é recrutado, treinado, contratado e remunerado numa outra lógica e coordenação - , aliada às idiossincrasias de cada uma das corporações, dificulta o processo de comunicação e a interação entre as pessoas, comprometendo, em última instância, o trabalho cooperativo de equipe.

É interessante observar que, nesse contexto de baixa articulação, o grupo de técnicos de enfermagem acaba por funcionar como um elo entre médicos, enfermeiros e pacientes e, conseqüentemente, é o que vivencia mais intensamente este conflito.

\section{A qualificação}

A qualificação para o trabalho é tema que ocupa grande espaço na literatura sobre a reorganização do mundo do trabalho e aparece de forma recorrente no discurso de trabalhadores, gestores e dirigentes como um ponto crítico no processo de trabalho. Todos preconizam, recomendam e demandam ações de treinamento, cursos e processos de educação continuada.

Do total de entrevistados, $90 \%$ dos médicos, $60 \%$ dos enfermeiros e $26 \%$ dos técnicos participaram de pelo menos uma atividade técnico-científica nos últimos seis meses.

Foram criados dois programas de educação continuada, um Projeto de Educação Continuada para Enfermagem e um Programa de Treinamento Avançado para os médicos. Ambos foram iniciativas da equipe médica, sendo coordenadas por ela.

O treinamento oferecido pelo primeiro é ministrado pelos médicos e tem caráter teórico. Os conteúdos dizem respeito às tecnologias e processos realizados na Unidade Coronariana - princípio de funcionamento dos aparelhos, sua finalidade, efeitos secundários e cuidados de enfermagem demandados. Este conhecimento é que possibilitará integrar o saber e o fazer, sobretudo para os técnicos. No entanto, está referenciado pelo domínio das bases científicas que o orientam.

Ao discutir as transformações dos conteúdos profissionais e dos ofícios, Zarifian (1998a) refere-se a um intenso debate ocorrido na década de 80 sobre o impacto da automatização e informatização na redefinição dos ofícios. Alguns defendiam a idéia de que a competência estaria no domínio técnico dos 
novos equipamentos, enquanto outros sustentavam que os novos equipamentos exigiriam um conhecimento mais aprofundado sobre o processo nos quais estariam sendo aplicados. Para estes últimos, a competência consistiria no domínio mais aprofundado dos processos característicos de cada setor.

Esta discussão nos remete a uma reflexão não apenas sobre o processo de trabalho, mas sobre o processo de qualificação para o trabalho, que envolve uma discussão ampla, que não se restringe à capacitação tecnológica, mas compreende um debate maior sobre a formação acadêmica dos profissionais de saúde, neste caso da formação do técnico.

Em relação ao processo de capacitação em serviço, ao analisarmos a participação dos trabalhadores nas atividades da educação permanente, observamos um baixo índice de participação dos técnicos nas ações de treinamento.

Isto se deve, em grande parte, ao modo de organização do trabalho, que não está estruturado de forma a reservar parte da carga horária para atividades de desenvolvimento de pessoal. Esta não é uma questão própria deste setor, apenas mais uma contradição do processo de transformação do trabalho. Organizados para atender a lógica do trabalho manual, os tempos e movimentos são rigorosamente planejados, não havendo espaço previsto na rotina para outras atividades, classificadas como 'atividades extras'. Incorporar o processo de formação e qualificação ao cotidiano dos serviços implica redirecionar ações, redimensionar o quadro de pessoal e, possivelmente, aumentar custos.

O que se observa, então, na maioria das organizações, é que a qualificação é oferecida, mas não se criam condições objetivas para que ela aconteça de forma eficaz, pois não há como o trabalhador se afastar do trabalho para freqüentá-la.

Assim, a responsabilidade pelo desenvolvimento na carreira passa a ser individual, embora a possibilidade de acesso esteja diretamente ligada à posição do trabalhador na organização e à sua inserção no processo de trabalho. Quanto maior a flexibilidade e autonomia de cada posto de trabalho, mais fácil será o acesso a novas experiências e a possibilidade de crescimento intelectual e vice-versa, o que de certa forma explica o maior envolvimento dos médicos, um envolvimento menor dos enfermeiros e a pouca participação dos técnicos.

\section{A comunicação}

Partindo do pressuposto de que a comunicação entre os agentes é inerente ao processo de trabalho coletivo, a questão a ser analisada era em que medida esta comunicação estaria sendo realizada como uma busca de consenso em torno do projeto e do objeto de ação. 
A relação entre a intervenção técnica e a forma de comunicação entre os agentes é um fator determinante no sentido de um agir mais instrumental ou comunicativo. Pode ser analisada numa perspectiva mais tecnicista, voltada para a elaboração de produtos técnicos, ou humanista, voltada para a melhor compreensão da complexidade do homem no trabalho.

A Tabela 3 mostra as formas de comunicação mais utilizadas na Unidade Coronariana, na perspectiva dos trabalhadores.

Tabela 3

Formas de comunicação interna utilizadas pelas equipes da Unidade Coronariana por categoria profissional

\begin{tabular}{lcccc}
\hline Formas de comunicação & Médicos & Enfermeiros & Técnicos & Total \\
\hline Através de relatórios & - & 3 & 3 & 6 \\
Através de reuniões & 7 & 4 & 5 & 1 \\
Através das chefias & 5 & 2 & 10 & 20 \\
Prontuários & 1 & 3 & 4 & 16 \\
Informalmente entre os integrantes & 9 & & - & 3 \\
\hline
\end{tabular}

O modelo hierarquizado em que as instituições tradicionalmente se organizam, sobretudo as instituições de saúde, por meio de uma agregação vertical de profissões ou grupos de especialistas, se reflete na forma de comunicação nas equipes e entre equipes.

Enquanto os médicos utilizam com mais freqüência mecanismos informais de comunicação entre eles (75\%), a equipe de enfermagem usa instrumentos formais da hierarquia para se relacionar no trabalho.

Nestes casos, segundo Campos, há uma tendência à burocratização dos mecanismos de comunicação: cada grupo elabora seus próprios regulamentos, objetivos e normas, e os protocolos e programas normativos de conduta passam a ter "a função mágica de integrar o desarticulado em si mesmo" (Campos, 1997, p. 248).

Observamos que, assim como relatado por Peduzzi (1998), a comunicação nos serviços de assistência em saúde ocorre, principalmente, entre os agentes de uma mesma área profissional: médicos com médicos, enfermagem com a enfermagem. Um exemplo dessa segmentação é a dinâmica dos prontuários, que, em princípio, são o instrumento formal de comunicação e acompanhamento das ações em cada caso particular.

As reuniões clínicas e reuniões de equipe são potenciais espaços para discussão do projeto e uma oportunidade de construção de consensos acerca não apenas do trabalho prescrito, mas, sobretudo, do trabalho real e dos conflitos dele decorrentes. No entanto, da mesma forma que nas atividades 
de treinamento, a participação dos trabalhadores se dá de maneira diferenciada em relação às categorias profissionais e é inversamente proporcional ao grau de flexibilidade e autonomia dos processos de trabalho de cada uma delas.

De acordo com estes registros, participam das reuniões $100 \%$ dos médicos, $80 \%$ dos enfermeiros e apenas $21 \%$ dos técnicos.

Segundo os profissionais entrevistados, são realizadas reuniões clínicas semanais, organizadas pela equipe médica, e reuniões quinzenais da enfermagem, sendo que as demais não têm periodicidade definida.

A questão da comunicação entre as equipes e entre as pessoas é um dado a ser refletido na perspectiva das novas formas de organização do trabalho. Os sistemas de informação estão estruturados em função do sistema de custos, e as regras de linguagem, restritas aos grupos corporativos, impondo um silêncio tácito que dificulta agregar valor, conhecimento e, sobretudo, pessoas.

Por outro lado, falar sobre o trabalho é difícil para seus agentes. Não que lhes faltem palavras ou tenham déficits lingüísticos, mas, ao se traduzir uma experiência singular numa linguagem coletiva, nem sempre se encontra material semiótico apropriado à disposição (Boutet, 1993).

O terceiro elo na cadeia de comunicação no trabalho em saúde é o paciente/cliente, objeto e ao mesmo tempo sujeito da ação dos trabalhadores, uma vez que é ele quem dará o significado e a razão da ação de cada um.

A comunicação, portanto, é inerente à vida profissional e, sobretudo, ao trabalho em saúde. A comunicação entre indivíduos, profissionais e clientes se dá das mais diferentes formas, e a maneira como se realiza é determinante na estruturação das redes de comunicação. Zarifian (1998a) chama a atenção para o fato de que estas redes só funcionarão quando as pessoas tiverem aprendido a conhecer os pontos de vista uns dos outros, suas preocupações, suas limitações e começarem a identificar os problemas comuns nos quais estejam interessadas em trabalhar juntas.

\section{As estratégias de defesa}

A discussão sobre o sofrimento e o desgaste do trabalho vem sempre referenciada na literatura pelo modelo industrial, estando o sofrimento psíquico relacionado à baixa capacidade do trabalhador de interferir na organização do trabalho, tendo que se submeter e se restringir ao trabalho prescrito. A centralidade da atividade de assistência faz com que as relações existentes no interior de um hospital sejam também permeadas por elementos externos, do presente e do passado, que irão se relacionar com a vida de seus personagens como um todo e que poderão ser apreendidos pelas vivências internas ao 
hospital. Isso faria com que, além dos novos dilemas sobre como estabelecer um bom atendimento ao paciente, se retomassem, com mais intensidade, antigos problemas que se referem a como e o quê priorizar: a ciência, a atenção, o suporte à dor e ao sofrimento? (Machado e Correa, 2000).

Para preservar o equilíbrio psíquico, os trabalhadores acabam por elaborar estratégias defensivas pautadas em mecanismos de sublimação. São processos que, embora vividos individualmente, se realizam no campo social e, portanto, exigem reconhecimento dos pares (Déjour, 1987).

A primeira estratégia a considerar é o distanciamento em relação ao paciente, que passa a ser encarado como objeto da ação dos profissionais que o assistem. Com apoio em protocolos, regulamentos e normas internas, a tendência é apagar qualquer traço de subjetividade presente na relação médico/paciente. Para esse autor, o trabalho em saúde - que, por sua natureza, coloca o homem frente a situações que potencializam seus medos e angústias - , ao ser racionalizado e cada vez mais normalizado, limita e aliena o trabalhador em relação à sua produção (Campos, 1997).

A segunda estratégia defensiva observada estava centrada na forma de encarar o paciente. Embora ao chegarem ao setor sejam vistos como consumidores exigentes, os clientes, por serem submetidos às rotinas de atendimento, passam imediatamente à categoria de pacientes, isto é, dependentes daqueles que os assistem. No caso do paciente coronariano, a fragilidade com que chega ao setor, aliada ao medo e à insegurança que daí advêm, contribui para uma assimetria nas relações entre profissionais e pacientes, com uma tendência à infantilização destes.

A terceira 'regra' observada no cotidiano da Unidade Coronariana, que se estende a todos os setores que trabalham com a proximidade e o risco da morte, é a 'banalização', por meio de um vocabulário próprio ou do tratamento automático das situações com que os profissionais são obrigados a lidar.

Outra forma de reagir é o silêncio. É como se houvesse uma metalinguagem subentendida naquele silêncio e naquela postura. Uma das principais questões levantadas pelos trabalhadores, sobretudo pelos técnicos de enfermagem, é a falta de retorno de pacientes e dos próprios médicos em relação ao seu desempenho e à sua dedicação.

Os depoimentos e observações feitas no cotidiano do trabalho dos profissionais que atuam em serviços deste nível de complexidade e risco mostram que a aparente 'frieza' desenvolvida por todos, analisada como estratégia de sobrevivência, esconde, na verdade, um conflito, permeado pelas relações intersubjetivas, inerentes ao trabalho em saúde. 


\section{Considerações finais}

Apresentamos, a seguir, algumas considerações, a partir da análise do material e da discussão feita no desenvolvimento do tema, buscando responder às questões que motivaram o estudo, bem como trazer as novas questões que dele emergiram, a saber, a tecnologização da assistência, o trabalho em equipe, as mudanças na qualificação do trabalho e do trabalhador, a incorporação do conceito de competência, o desenvolvimento profissional e a reestruturação do trabalho, a valorização do trabalho e do trabalhador, e as relações subjetivas e o processo de comunicação.

Quanto à primeira questão - a tendência tecnologizante do processo de trabalho no campo da assistência médica - identificada por meio do estudo empírico, não está restrita apenas à introdução e à utilização de equipamentos de ponta. Também está referida por um agir instrumental baseado na racionalização e padronização de procedimentos e comportamentos, e se expressa nos protocolos, na normalização e, sobretudo, no controle.

O discurso científico utilizado como legitimador da prática e diferencial no mercado reforça a hegemonia da razão técnico-científica, que, segundo Habermas (1968), é usada como instrumento de dominação, mas pode funcionar como uma força positiva, desde que seus fins sejam discutidos num contexto democrático.

A pergunta que fica é como reverter esse processo no sentido de uma ação interativa, de forma a possibilitar a intercompreensão, que, para Déjour (1997), constitui de certa forma a condição sine qua non de uma deliberação, uma discussão ou um debate racionais.

Embora não tenha sido objeto deste estudo, a segunda questão — o trabalho em equipe - geralmente associado à assistência à saúde, principalmente no espaço hospitalar, se caracterizou, na estrutura estudada, pelo modelo tradicional, em que os médicos, mesmo numericamente menores em comparação aos demais profissionais, detêm o monopólio sobre as atividades no âmbito dos cuidados e da prescrição destes.

No entanto, se tomarmos como referência a dinâmica e a estruturação da equipe médica na situação estudada, podemos identificar uma mudança na dinâmica do serviço e na forma como os profissionais se relacionam, entre si e com o trabalho, no sentido da construção de um projeto coletivo.

A perspectiva de desenvolvimento profissional e de legitimação científica do trabalho, fortemente impulsionada pela jovialidade da equipe, levou esse grupo a se reunir e a discutir de forma conjunta a orientação do trabalho, para um agir interativo. A abertura desta experiência para a equipe ampliada surge como desejo no discurso dos coordenadores médicos, mas não se efetiva na prática, pois permanece internalizado pelos profissionais das 
diferentes categorias profissionais, inclusive os próprios médicos, o modelo hierarquizado e assimétrico de assistência médica.

Apesar do fator estrutural apontado acima, essa experiência dos médicos, mesmo isolada e segmentada, a nosso ver pode ser identificada como um sinal do início de uma transição no modo de operar das equipes em serviços de saúde de maior complexidade, no sentido de uma ação mais interativa.

No tocante à terceira questão - as mudanças na qualificação do trabalho e do trabalhador - a observação do trabalho real nos leva a concluir que, na experiência estudada, há uma mescla entre os dois paradigmas tecnológico e fordista - na organização do trabalho. Por um lado, o trabalhador continua executando sua tarefa manual ou mecanicamente, administrando os movimentos próprios ou da máquina - no caso, dos equipamentos. Por outro, dependendo da tecnologia utilizada e do posto de trabalho ocupado, o trabalhador passa a monitorar as operações e a gerir o processo, mais do que executá-lo.

Esta variação pode ser avaliada na perspectiva de um continuum que varia em função da inserção do profissional na equipe. Embora o trabalho em saúde, no campo da assistência hospitalar, tenda a se aproximar do paradigma tecnológico, sua organização interna caracteriza-se por uma polarização entre o trabalho complexo e especializado, e o trabalho manual sem qualificação específica.

Do grupo de enfermagem é exigido um papel mais técnico e menos burocrático, com base na assistência e na competência técnica. No entanto, o processo de trabalho permanece estruturado no paradigma taylorista-fordista, instala-se um conflito entre o discurso (tecnológico) e a prática (fordista), que, em última instância, reflete o conflito entre o trabalho prescrito e o trabalho real.

Ainda quanto a essa questão, a pesquisa sinaliza a necessidade de um trabalhador qualificado, capaz de se responsabilizar por processos cada vez mais amplos e integrados, estando a competência profissional centrada mais no processo do que na operação dos equipamentos. Para isto é necessário um domínio dos conceitos básicos que informam os processos, garantidos por uma sólida educação geral e básica, o que, para Deluiz (1995), permite a transferência de qualificações e a possibilidade de enfrentar diferentes alternativas tecnológicas.

Do ponto de vista da escolaridade e da especialização, é importante ressaltar que a categoria de auxiliar de enfermagem não integra o conjunto de postos de trabalho do hospital estudado, nem de instituições congêneres. As equipes de enfermagem só operam com técnicos e enfermeiros, e a discussão sobre o novo perfil das equipes sugere, em alguns momentos, a figura do tecnólogo, que já é uma realidade no setor de imagens. Esta situação, em si, revela uma mudança no perfil da força de trabalho e tendências em relação à intelectualização do trabalho. 
Diante deste quadro, cabe uma reflexão sobre o processo de trabalho e a clássica divisão entre o trabalho do enfermeiro, do técnico e do auxiliar. Como se situam estas categorias no contexto das novas formas de organização do trabalho e que competências - já apontando para quarta questão por nós levantada — são necessárias para o seu desempenho?

Quanto à experiência, embora apontada como referência para o trabalho em serviços de maior complexidade, não existe qualquer sistema formal ou informal para sua aferição.

Considerando não só as mudanças na organização dos serviços, em que a competência de cada trabalhador tem impacto no produto final - que é a assistência de qualidade com resolutividade —, mas também o caráter subjetivo e intersubjetivo das ações de saúde, o modelo reducionista da competência profissional utilizado como sinônimo de qualificação stricto sensu não responde às necessidades do trabalho real.

O conceito de competência utilizado na literatura atual16, que se traduz na capacidade do trabalhador para articular e mobilizar conhecimentos, habilidades e atitudes frente a situações concretas de trabalho não previstas, de forma a resolvê-las, representa uma referência importante para se repensar a organização do trabalho em saúde e as formas de atuação de seus agentes diante das transformações do processo de trabalho.

Como avaliar e promover o desenvolvimento dessas novas competências nos espaços de trabalho e como garantir uma uniformidade neste processo de qualificação, de forma a permitir mobilidade e circulação dos trabalhadores no mercado de trabalho setorial? Estas são questões que se apresentam para os formuladores e gestores de políticas setoriais, no campo da saúde e da educação.

No que diz respeito ao desenvolvimento profissional e à reestruturação do trabalho, na perspectiva da estruturação dos serviços e dos conteúdos oferecidos pelos programas de capacitação, dois pontos fundamentais nos chamaram a atenção: o confronto entre a qualificação utilizada e a requerida no cotidiano do trabalho, sobretudo o da enfermagem, frente ao novo paradigma do trabalho em termos de competência profissional; e o conflito entre um modelo instrumental de capacitação orientado para o domínio da técnica, típico do modelo fordista, no qual os trabalhadores foram preparados, e o modelo voltado para a compreensão dos processos, orientado para o conhecimento e a reflexão sobre os conceitos que embasam os mesmos, introduzidos na proposta de capacitação do modelo tecnológico.

Em relação ao primeiro, a principal conseqüência é que as propostas de capacitação não emergem dos problemas identificados no desempenho da tarefa pelos agentes, mas de agentes externos ou categorias profissionais que dominam o processo em sua totalidade - no caso, os médicos. Assim, embora reconhecida a necessidade de capacitação em serviço e no serviço, esta prática não integra a rotina de trabalho da equipe de enfermagem, cabendo 
ao trabalhador viabilizar sua participação em termos da compatibilização de horários e cumprimento das tarefas prescritas, assumindo individualmente a responsabilidade por seu desenvolvimento profissional.

Em relação ao segundo, o que se observa é que os técnicos não estão preparados do ponto de vista da sua formação básica para interagir neste novo processo, porque lhes faltam instrumentos conceituais que possibilitem refletir sobre os novos processos e relacioná-los. Assim, a relação entre processos cognitivos e o uso de modernas tecnologias extrapola o espaço das empresas e organizações e deve ser entendido na perspectiva social em que estas relações se inscrevem.

Esta discussão nos leva a concluir pela importância do processo de capacitação adequado ao contexto de transição tecnológica e pela necessidade de comprometer trabalhadores e gestores com o processo de qualificação, individual e coletivo, orientado para o desenvolvimento de competências nos níveis técnico, organizacional, comunicativo, social, pessoal, de cuidado, de serviço e sociopolítico (Deluiz, 2001).

Quanto à quinta questão apontada — valorização objetiva das ações e dos indivíduos, traduzida nos mecanismos de remuneração - mais uma vez, são duas as principais contradições do sistema que têm rebatimento direto sobre a remuneração do trabalho.

A primeira se refere à valorização do produto do trabalho em saúde. Em que pese o paradigma da qualidade como diferencial numa situação de mercado, este não é um indicador considerado na remuneração das ações de saúde pelos agentes do mercado. Assim, a composição da equipe, sua qualificação e o sucesso e resolutividade dos procedimentos não são considerados no cálculo dos valores a serem reembolsados, sendo o custo deles de responsabilidade do prestador. Num cenário político e econômico em que os consumidores têm baixo poder de negociação e as alternativas de escolha são limitadas, a valorização do trabalho e do trabalhador passa a não constituir uma prioridade, pois o retorno do investimento é reduzido.

A segunda está diretamente relacionada à primeira e se refere às diferentes formas de inserção no mercado de trabalho e à conseqüente falta de perspectiva de carreira, bem como de remuneração diferenciada. A tendência à terceirização dos serviços no ambiente hospitalar, adotada basicamente no serviço médico, reduz a capacidade de negociação por categoria e entre categorias, além de potencializar a histórica divisão entre as equipes médicas e de enfermagem.

Do ponto de vista subjetivo, o desafio é como reaproximar os trabalhadores do resultado de seu trabalho, no sentido de valorizar o orgulho profissional pelo esforço singular realizado em cada caso, como avaliar o trabalho em saúde e como transformar esta avaliação em recompensa para os trabalhadores (Campos, 1997). 
Por fim, quanto à última questão - as relações subjetivas e o processo de comunicação - consideramos que o trabalho em saúde distingue-se entre os demais ofícios por haver sempre 'um outro' diretamente implicado e, portanto, um cruzamento de subjetividades em um contexto especial, em que as relações interpessoais estão presentes durante todo o tempo (Campos, 1997).

No entanto, a reificação da tecnologia, por meio da hipervalorização das técnicas de objetivação, padronização e uniformização, tem contribuído para que as relações intersubjetivas sejam colocadas em segundo plano, e a subjetividade, assim como a perspectiva do cliente sejam pouco consideradas na assistência.

As conseqüências deste modelo são a falta de motivação e o aumento do sofrimento no trabalho, reforçando-se com isso a alienação própria do modelo fordista, fortemente arraigado. O que se observa é que o processo de comunicação - que tradicionalmente no âmbito hospitalar ocorre de forma segmentada, por categoria e através de uma estrutura hierarquizada - passa a ser mediado pela técnica, aumentando ainda mais a distância entre os diferentes agentes do processo de trabalho e, assim, diminuindo a possibilidade de trocas intersubjetivas.

A incorporação tecnológica é um processo inerente ao trabalho em saúde, podendo ocorrer em tempos e intensidade diferentes, dependendo do contexto político, econômico e social em que estejam inseridos os serviços, bem como o modelo assistencial vigente. Não se trata, portanto, de atribuir a esse processo um juízo de valor, mas, sim, de estar atento para seus riscos e possibilidades, e ter clareza do projeto que se deseja construir, colocando o processo de incorporação tecnológica a serviço desse projeto. Neste sentido, recuperamos o pensamento de Habermas (1968), segundo o qual a razão técnico-científica pode funcionar como uma força positiva, desde que seus fins possam ser discutidos num contexto democrático.

Retomando a questão exposta inicialmente sobre o papel do trabalhador de nível médio17 e as novas exigências que se apresentam a ele frente à reorganização do trabalho, destacamos dois pontos importantes, identificados no decorrer da pesquisa e que merecem uma reflexão.

$\mathrm{O}$ primeiro refere-se às mudanças no processo de trabalho desta categoria profissional. Quanto ao aspecto qualitativo do trabalho, pode-se afirmar que não há no cotidiano uma aparente modificação das rotinas e atividades, permanecendo a fragmentação que caracteriza o processo de trabalho em saúde. Tal fragmentação se evidencia em diferentes dimensões: conceitual separação entre o pensar e o fazer; técnica - especialização; social — relações rígidas de hierarquia e subordinação 18 .

No entanto, acrescenta-se à atividade de rotina outra dimensão do trabalho destes profissionais: a capacidade de atuar em situações não previstas, utilizando, além do conhecimento técnico específico, saberes empíricos, prá- 
ticos, habilidades e experiências. As novas habilidades e conhecimentos exigidos dos trabalhadores de nível médio, na situação de trabalho estudada, não requerem uma qualificação técnica nova, específica, mas, sim, atitudes de comportamento e atributos de personalidade como atenção, vigilância, senso de responsabilidade, capacidade de previsão e experiência de trabalho.

O outro aspecto diz respeito ao sofrimento psíquico a que estes profissionais estão submetidos cada vez mais e o conseqüente distanciamento deles em relação ao paciente, como uma estratégia de defesa. Este 'estranhamento' frente à situação do sofrimento alheio é uma forma de defesa e sobrevivência psíquica dos profissionais de saúde, que, apoiados em protocolos, regulamentos e normas internas, tendem a apagar qualquer traço de subjetividade presente em sua relação com o paciente (Campos, 1997).

Por outro lado, as novas práticas racionalizadoras que acompanham as novas tecnologias favorecem a objetividade das relações e o distanciamento. Este, se levado às últimas conseqüências, pode comprometer a humanização do atendimento, acabando por gerar outro tipo de conflito e sofrimento ao trabalhador.

Assim, a defesa da vida deveria constituir o componente obrigatório de responsabilidades de todo e qualquer profissional de saúde (Campos, 1997). Nesta perspectiva, por mais que a racionalidade técnica possa influenciar os sistemas de organização e gestão dos serviços no campo da saúde, a convergência do reconhecimento intersubjetivo entre os participantes do processo de trabalho e o sentido deste constituem a dimensão essencial da atividade cotidiana de assistência à saúde. 


\section{Notas}

1 Pesquisadora titular e assessora da Vice-Presidência de Ensino e Recursos Humanos da Fiocruz, doutora em Saúde Coletiva pelo Instituto de Medicina Social da Uerj. <mines@ fiocruz.br>.

2 Sobre o assunto, ver Boyer e Durand, 1993; Gorender, 1997; Mattoso, 1995.

3 Sobre o assunto, ver Deluiz (1995).

4 A pesquisa de campo realizou-se de fevereiro a maio de 2001.

5 O primeiro, trabalho prescrito, diz respeito às normas técnico-organizativas repassadas ao trabalhador; o segundo, trabalho real, refere-se à adaptação das mesmas à realidade da situação de trabalho: "o real é a parte da realidade que resiste à simbolização" (Déjour, 1997, p. 41).

6 Déjour (1990, p. 134) chama de "ressonância simbólica".

7 As estratégias defensivas dizem respeito às regras e normas desenvolvidas pelos trabalhadores, consensuadas e apropriadas coletivamente, de forma a reagir e a minimizar o sofrimento e os riscos vivenciados e identificados por eles em sua prática.

8 Andrew Gonczi (1997) faz esta discussão no nível do processo educacional baseado em competências.

9 Foram entrevistados o diretor médico do Hospital e os diretores/coordenadores da Unidade Coronariana e Emergência do Centro Cardiológico.

10 Foram entrevistados os coordenadores: técnico (médico), científico (médico), enfermagem intensivista (enfermeiro), enfermagem (enfermeiro), administrativo (engenheiro), recursos humanos (psicólogo), educação continuada (enfermeira), enfermagem da hemodinâmica (enfermeira), acreditação hospitalar (médico).

11 Os médicos sócios não trabalham diretamente nas atividades de assistência na rotina diária.

$12 \mathrm{O}$ oitavo enfermeiro é o coordenador da equipe de enfermagem intensivista e não está diretamente ligado às atividades de assistência.

13 Peduzzi (1998) observou esse processo ao estudar o trabalho coletivo em uma unidade de terapia intensiva pediátrica. Fazendo referência aos quadros de parada respiratória, relata a cooperação, cumplicidade e solidariedade entre os agentes envolvidos diretamente na atenção à criança: “Trata-se de trazer a criança de volta à vida e não há tempo para questionamentos, conversas ou hostilidades de nenhuma natureza" (p. 166).

14 Foi apresentada aos entrevistados uma relação de habilidades para que eles as colocassem em ordem de prioridade.

15 O saber ser (saber social): incorpora os saberes sociais, nele compreendidas a capacidade de se organizar, de se comunicar, as representações, as referências culturais e subjetivas. 
16 “a capacidade de enfrentar — com iniciativa e responsabilidade, guiadas por uma inteligência prática do que está ocorrendo e com capacidade para coordenar-se com outros atores para mobilizar suas capacidades - situações e acontecimentos próprios de um campo profissional" (Zarifian, 1990).

17 No caso específico deste estudo dos técnicos de enfermagem.

18 Esta discussão pode ser aprofundada em Quintana, Roschke e Ribeiro (1994).

\section{Referências}

BOUTET, Josiane. 1993. Atividade de linguagem e atividade de trabalho. Educación Permanente, n. 116.

BOYER, Robert; DURAND, Jean Pierre. 1993. L'après-fordisme. Paris: Syros, Alternatives Economiques.

CAMPOS, Gastão Wagner. 1997. Subjetividade e administração de pessoal: considerações sobre modos de gerenciar o trabalho em equipe de saúde. In: MERHY, Emerson; ONOCKO, Rosana (orgs.) Agir em saúde: um desafio para o público. São Paulo: Hucitec.

DAL POZ, Mario; MARTINS, Maria Inês. 1998. A qualificação dos trabalhadores de saúde e as mudanças tecnológicas. Physis: Revista de Saúde Coletiva, v. 8, n. 2, p. 125-146.

DEJOUR, Christophe. 1987. Note de travail sur la notion de souffrance. In: Plaisir et souffrance dans le travail. Tome I. Paris: CNRS.

; ABDOUCHELI, Elisabeth. 1990. Itinerário teórico em psicopatologia do trabalho. Tradução de D. M. Glina. Prevenir, n. 20

1997. O fator humano. Rio de Janeiro: Fundação Getúlio Vargas.

DELUIZ, Neise. 1995. Formação do trabalhador: produtividade \& cidadania. Rio de Janeiro: Shape.
1996. A globalização econômica e os desafios à formação profissional. Boletim Técnico do Senac, v. 22, n. 2.

1997. Mudanças no mundo do trabalho e necessidades de qualificação dos trabalhadores de saúde. Texto apresentado na Reunión de la Red Latino Americana de Técnicos en Salud. Rio de Janeiro: OPS/ OMS - Fiocruz, 4 a 6 de set. (Mimeo.) . 2001. Qualificação, competências e certificação: visão do mundo do trabalho. Revista Formação, v. 1, n. 2, p. 5-16.

DEPRESBITERIS, Léa. 2001. Certificação de competências: a necessidade de avançar numa perspectiva formativa. Revista Formação, v.1, n. 2, p. 27-37.

GONCZI, Andrew. 1997. Enfoques de educación y capacitación basada en competencia: la experiencia australiana. In: Formación basada en competencia laboral. Montevideo: Cinterfor.

MERTENS, L. 1996. Competencia laboral: sistemas, surgimiento y modelos. Montevideo: Oficina Internacional del Trabajo (Cinterfor).

GORENDER, Jacob. 1997. A globalização tecnologia e relações de trabalho. Estudos Avançados. São Paulo, v. 11, n. 29, s/p.

HABERMAS, Jürgen. 1968. Técnica e ciência como ideologia. Lisboa: Edições 70.

LARANGEIRA, Sonia Maria. 1997. Qualifica- 
ção. In: CATTANI, A. D. (org.) Trabalho e tecnologia: dicionário crítico. Petrópolis: Vozes.

LIMA, Júlio. 1997. Formação técnica na Escola Politécnica de Saúde Joaquim Venâncio. Texto elaborado para o Seminário Formação Técnica em Ciência e Tecnologia em Saúde: Perspectivas e Tendências no Mundo do Trabalho. Rio de Janeiro: EPSJV/Fiocruz. (Mimeo.)

MACHADO, Jorge Mesquita; CORREA, Marilena. V. 2000. Reflexões sobre a observação do processo de trabalho: introduzir o conceito de vida no trabalho na análise das relações entre processo de trabalho em saúde In: Seminário Nacional Saúde Ambiente e Processo de Desenvolvimento, Rio de Janeiro. Anais. Rio de Janeiro: Fundação Osvaldo Cruz.

MATTOSO, Jorge. 1995. A desordem do trabalho. São Paulo: Scritta.

PEDUZZI, Marina. 1998. Equipe multiprofissional de saúde: a interface entre trabalho e interação. Tese de Doutorado, Campinas: Faculdade de Ciências Médicas, Universidade Estadual de Campinas.

PIRES, Denise. 1996. Processo de trabalho em saúde, no Brasil, no contexto das transformações atuais na esfera do trabalho. Tese de Doutorado, Campinas: Instituto de Filosofia e Ciências Humanas da Universidade Estadual de Campinas.

1998. Reestruturação produtiva e trabalho em saúde no Brasil. São Paulo: Confederação Nacional dos Trabalhadores em Seguridade Social/CUT/Annablume.
QUINTANA, Pedro; ROSCHKE, Maria Alice; RIBEIRO, Eliana Claudia. 1994. Educación permanente, proceso de trabajo y calidad de servicio en salud. In: HADDA, Q. J. et al. (Orgs.) Educación permanente de personal de salud. Washington: OPS.

RAMONET, Ignacio. 1998. O pensamento único e os regimes globalitários. In: Textos de Conferências do Seminário Globalização o Fato e o Mito. Programa Universitário de Estudos Estratégicos Uerj/ UFRJ. Rio de Janeiro. (Mimeo).

ROVERE, Mario. 1992. Planificacion estrategica de recursos humanos en salud. Washington: Programa de Desarrollo de Recur-sos Humanos de Salud/OPS, jun.

ZARIFIAN, Philippe. 1998a. A gestão pela competência. In: Seminário Internacional Educação Profissional, Trabalho e Competência. Anais. Rio de Janeiro: Senai/DNCIET.

1998b. O modelo de competência e suas conseqüências sobre ofícios profissionais. In: Seminário Internacional Educação Profissional, Trabalho e Competência. Anais. Rio de Janeiro: Senai/DNCIET. 1990. As novas abordagens da produtividade. In: SOARES, R. M. S. M. (org.) Gestão da empresa: automação e competitividade. Brasília: Ipea- Iplan.

1991. Trabalho e comunicação nas indústrias automatizadas. Revista de Sociologia, v. 3, n. 1-2, p. 119-130.

Recebido em 09/02/2004

Aprovado em 20/07/2004 